\title{
Plant Allelochemical Interference: Allelopathy
}

ISSN: 2637-7659

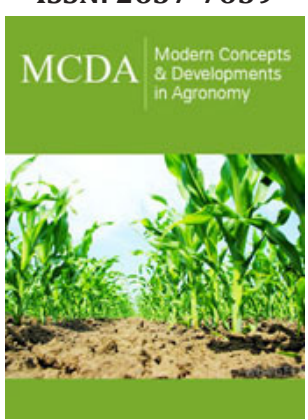

*Corresponding author: Fulya Başaran, Researcher, Atatürk Horticultural Central Research Institute, Yalova, Turkey

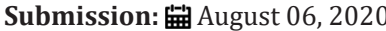

Published: 眥September 28, 2020

Volume 7 - Issue 3

How to cite this article: Fulya Başaran. Plant Allelochemical Interference: Allelopathy. Mod Concep Dev Agrono. 7(3). MCDA. 000663. 2020. DOI: 10.31031/MCDA.2020.07.000663

Copyright@ Fulya Başaran, This article is distributed under the terms of the Creative Commons Attribution 4.0 International License, which permits unrestricted use and redistribution provided that the original author and source are credited.

\section{Fullya Bașaran*}

Plant Protection Department, Atatürk Horticultural Central Research Institute, Turkey

\begin{abstract}
Allelopathy, which is defined as the negative and positive effects of many secondary metabolites produced by plants, microorganisms, viruses and fungi on the development and growth of agricultural and biological systems, is a known phenomenon since ancient times. As a plant-to-plant interference, allelopathy is the inhibitory direct or indirect effects of another plant on germination, growth or development by secreting chemicals (Allelochemicals) into the environment. This paper includes a mini review on allelopathy as plant-plant interference.
\end{abstract}

Keywords: Allelopathy; Interference; Allelochemicals; Seconder metobolites; Inhibition

\section{Introduction}

All plants living in the same ecosystem are closely related and interacts. Environmental factors have effects on the relationship of plants with each other, as well as plants can affect environmental factors. One of these factors is allelopathy, which plays a role in plant-plant interaction. Allelopathy, which exists in both natural ecosystems and agroecoystems is the inhibition of germination, growth or development of the neighboring plant with allelochemicals which released into the enviroment by plant residues, evaporation, root exudation [1,2]. The term allelopathy was first used in 1937 by the Austrian scientist Hans Molisch in his book "Der Einfluss einer Pflanze auf die andere-Allelopathie (The Effect)", which he wrote about the negative effects of plants on each other based on some observations he made in the field. Molisch expressed the term "allelopathy", which is derived from the Greek words "allelon" (each other) and "pathos" (to suffer), by interacting with a neighboring plant biochemically and inhibiting its development [3]. But probably the most ancient sample of the inhibitory effect of a chemical released from one allelopathic plant to another is the effect of chickpea (Cicer arietinum) on weeds and devil's thorns (Tribulus terrestris) reported by Theophrastus (300BC) [4].

Chemicals released from allelopathic plants are called "allelochemicals". Allelochemical compounds are classified into 14 chemical categories [1]. These are; water-soluble organic acids, straight-chain alcohols, aliphatic aldehydes, and ketones; simple unsaturated lactones; long-chain fatty acids and polyacetylenes; benzoquinone, anthraquinone and complex quinones; simple phenols, benzoic acid and its derivatives; cinnamic acid and its derivatives; coumarin; flavonoids; tannins; terpenoids and steroids; amino acids and peptides; alkaloids and cyanohydrins; sulfide and glucosinolates; and purines and nucleosides [5]. Allelochemicals in allelopathic plants; It is likely to be found in almost all plant organs and their related tissues, including roots, rhizomes, leaves, stems, pollen, seeds, flowers, bark and buds [6]. Under environmental conditions, they are released into the environment through root exudation, leaching from dead or live plant tissues, and volatilization from the above ground plant parts and/or decomposition of plant material [7]. When allelochemicals reach the recipient plant, the most frequently affected functions are cell division, pollen germination, nutrient uptake, photosynthesis and specific enzyme function, production and balance of plant hormones, membrane stability and permeability, act of stomata, pigment synthesis, respiration, amino acid synthesis [6]. 
Allelopathic effects are defined as direct (narrowest meaning of allelopathy) allelopathic effect and indirect allelopathic effect. Its direct effects correspond to the most common sense of allelopathy, it is a plant-plant interaction. That is, one plant interacts with the other plant by producing chemicals. Indirect allelopathic effect; the allelochemicals released from the decomposed plant residues change as a result of the activities of microorganisms and affect the development of the other plant [8]. Allelopathy affects soil's chemical properties and microbial activities, plant species and diversity, plant populations and plant communities, leading to certain changes in the ecosystem [9]. It is especially important that exotic plants, which were brought by chance or hand, dominate and change the natural flora and become invasive in the region where it was first established [10]. Studies on the use of allelopathy as an alternative to chemicals in the control of pests, diseases and weeds are increasing in order to ensure agricultural efficiency and sustainability in agroecosystems. For this purpose, allelopathic plants can be used as alternation plants in crop rotation, as plant extracts and biopestiside, by being included in the intercropping method and as a cover crop plant [11]. In addition, more studies are needed to better understand the positive and negative effects of allelopathy on ecology. In order to reach the correct and sufficient result with allelopathic plants researches it is important to conduct researches in laboratory and field conditions together.

\section{Conclusion}

Allelopathy is an interesting phenomenon, especially with the changes it causes in biodiversity and natural vegetation. However, in the ecosystem, it is not enough to say that plants interference to each other is caused by allelopathy only by observations. Because this situation may have been caused by a competition between plants. For this reason, it is necessary to evaluate the indirect and direct effects of plants with allelopathic potential both in laboratory conditions and in the field. It will be beneficial to increase more detailed studies on the use of such an interesting issue that exists spontaneously in nature in order to control pests, diseases and weeds through the correct management in agricultural ecosystems.

\section{References}

1. Rice EL (1984) Allelopathy ( $2^{\text {nd }}$ edn), Acad Press Inc Orlando, Florida, USA, p. 422.

2. Meiners SJ, Kong CH, Ladwig LM, Pisula NL, Lang KA (2012) Developing an ecological context for allelopathy. Plant Ecology 213(8): 1861-1867.

3. Willis RJ (2007) The decline of allelopathy in the latter Nineteenth Century. The History of Allelopathy pp. 159-194.

4. Amb MK, Ahluwalia AS (2016) Allelopathy: potential role to achieve new milestones in rice cultivation. Rice Science 23(4): 165-183.

5. Chengxu W, Mingxing Z, Xuhui C, Bo Q (2011) Review on allelopathy of exotic invasive plants. Procedia Engineering 18: 240-246.

6. Ferguson JJ, Rathinasabapathi B (2003) Allelopathy: How plants suppress other plants. EDIS.

7. Weston LA (1996) Utilization of allelopathy for weed management in agroecosystems. Agronomy Journal 88(6): 860-866.

8. Inderjit, Weiner J (2001) Plant allelochemical interference or soil chemical ecology? Perspectives in Plant Ecology, Evolution and Systematics 4(1): 3-12.

9. Cheng F, Cheng Z (2015) Research progress on the use of plant allelopathy in agriculture and the physiological and ecological mechanisms of allelopathy. Frontiers Plant Science 6: 1020.

10. Ni GY, Zhao P, Huang QQ, Hou YP, Zhou CM, et al. (2012) Exploring the novel weapons hypothesis with invasive plant species in China. Allelopathy Journal 29(2): 199-214.

11. Jabran K, Mahajan G, Sardana V, Chauhan BS (2015) Allelopathy for weed control in agricultural systems. Crop Protection 72: 57-65. 